\title{
The Correlation Analysis on the Tourism Industry Development and Tobacco Sales, Taking Xishuangbanna Autonomous Prefectures as an Example
}

\author{
Luo Dong-hui ${ }^{1, a}$, Guo Hua ${ }^{1, b}$ \\ ${ }^{1}$ Kunming University of Science and Technology, Kunming, China \\ amrluo9955@126.com, b150114953@qq.com
}

Keywords: Tourism industry development, Tobacco sales, Correlation analysis

\begin{abstract}
In this paper, we use the method of questionnaire survey and correlation analysis to study the relationship between Tourism Industry development and tobacco sales in Xishuangbanna Autonomous Prefectures. The impact of Tourism Industry development to tobacco sales is divided into direct effect and indirect effect. We consider both the quantity influence and the structure influence from former two aspects. The result of the direct effect has shown that tourists are account for $10 \%$ of total tobacco consumption in Xishuangbanna, tourists' consumption amount is even higher and consumption structure is better than local resident. We then study the indirect effect by considering tourism's impact on Local Residents Disposable Income Level (LRDIL), and then study the difference in consumption structure between tourism regions and non-tourism regions. The results proved that residents in tourism region has a better consumption structure. Synthesizing the direct and indirect impact analysis, we get the conclusion that Tourism Industry development surely have a positive influence on tobacco sales in Xishuangbanna. Finally, we put forward some suggestions on effectively using the promotion effect of tourism industry.
\end{abstract}

\section{Introduction}

Xishuangbanna Autonomous Prefectures is a great prefecture for tourism, modern tourism is well developed. According to the statistic of Xishuangbanna Travel and Tourism Administration, during China's "Eleventh five-year plan" period, the prefecture has hosted 30.7216 million tourists from domestic and abroad, 1.26 times more than the "Tenth five-year plan" period (13.5725 million). The prefecture is now striving to develop tourism into a strategic pillar industry of the economy. Xishuangbanna is also one of the largest tobacco consumption prefectures of Yunnan Province. Tobacco industry in China is always the main source of tax revenue for the central and local governments, ranking to the front than other industries. The increasing of tobacco sales directly affect the local economic and social development.

So far, only a few literatures consider the correlation of tourism development and tobacco sales. According to the research of $\mathrm{Li}$ et al. (2009), foreign tourists have a trend to buy local cigarettes which provides a huge opportunity for tobacco sales especially in a tourism-leading region. They develop some innovative counterplans and measures to capture and make full use of this market, but do not systematically analyse influence forms and degree. Because there are no sufficient works proving the inner relationship between them, some researchers in another side hold an opposite view that tourism development does not have a impact or a significant impact on tobacco sales. The reason is explained in the work of Zhou et al. (2003). They believe that the proportion of cigarette customers in tourist population is not high, and tourists also generally have a strong healthy awareness, which build a barrier to fully develop the tourism market. Some even consider cigarette as a special commodity, the promoting effect of tourism industry to regional development cannot function well in tobacco sales.

This paper is focus on studying the influence relations between them. Two questionnaires are designed to get the relevant data from tourist and local residents respectively. We also get the overall accurate tobacco sales data from the V3 system of Xishuangbanna Tobacco Monopoly Bureau. Then the correlation is analysed via the process of data mining. The direct impact of tourism on tobacco 
sales is divided into two aspects: quantity influence and structure influence. The indirect impact analysis is conducted by taking into account tourism's impact on Local Residents Disposable Income Level and then considering LRDIL's influences on tobacco sales and structure variation. Finally, we come to the results to what extent does tourism development affect tobacco sales in Xishuangbanan Autonomous Prefectures.

\section{Model and Data}

The paper uses the results from the two questionnaires for tourists and local residents, and combines the data exported from the V3 system of Xishuangbanna Tobacco Monopoly Bureau which provides monthly tobacco supply data according to region and cigarette category. Because of the cigarette monopolization system in China, all selling channels in a certain distinct are counted, all data is regarded to be accurate.

The questionnaire survey is undertaken by assist from Xishuangbanna Tobacco Monopoly Bureau and Xishuangbanna Tourism Administration. 1195 copies of questionnaire are distributed, 600 copies for tourists and 595 copies for local residents. 420 copies for tourists are authorized to tour guides and travel services with emphasis on the activity of tobacco consumption and gift purchasing. The rest of 180 copies for tourists are surveyed by tobacco retailers in or near the tourist region. The 595 copies for local residents is focus on smoking resident population, taking by retailers in tourist and non-tourist region. Finally 362 copies of effective questionnaire for tourist and 247 copies for local residents have been got.

From the questionnaires we can also get the smoking proportion of these two groups. Smoking proportion of tourists can be directly judged by the option "smoke or not" in questionnaire. Local proportion is obtained by synthesizing the data from questionnaires and the data from summary table of tobacco retailers in V3 system. The Smoking proportion of tourists and local residents is 36.6\% and $35.2 \%$ respectively...Monthly average sales data in each region can be got form the V3 system, and it can be sorted by category.

\section{Direct Impact Analysis}

Direct impact of tourism on tobacco sales can be divided into two aspects: quantity influence and structure influence. Quantity influence indicates that cigarette consumption of tourists in Xishuangbanna directly increasing the total tobacco sales; structure influence refers to the improvement of tourism tobacco consumption structure (increasing of high-end tobacco sales) which brings benefits on prefecture tobacco consumption structure and then influences sales revenue. The mathematical models in this paper are developed on the basis of the following notations and assumption:

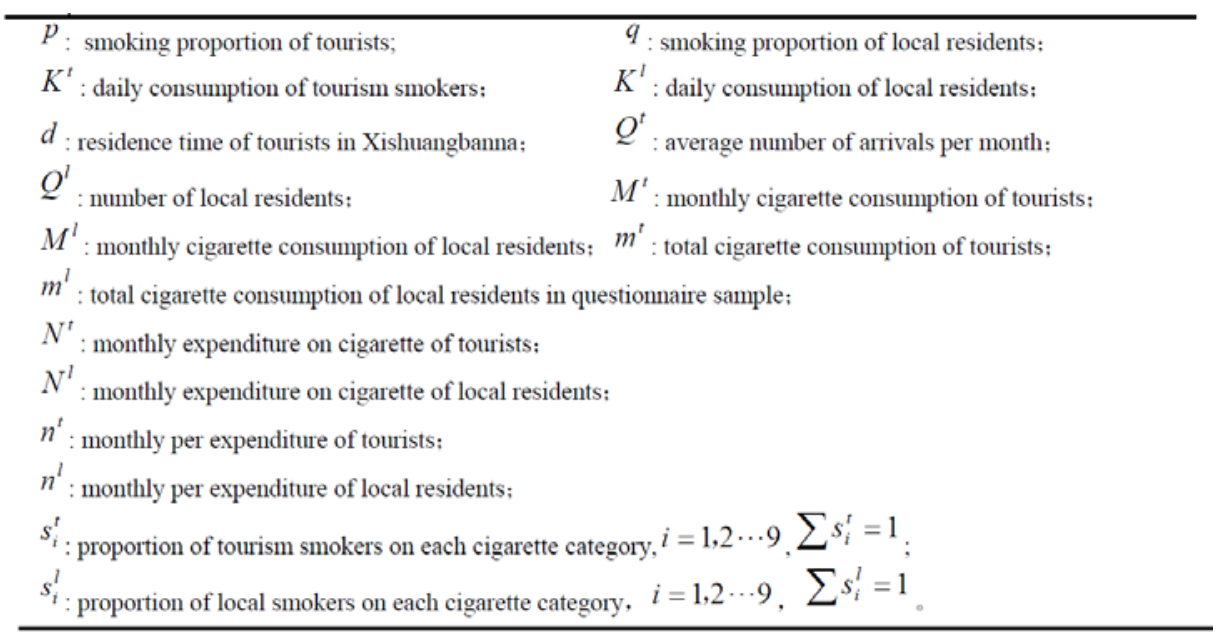

It is easy to obtain monthly cigarette consumption of tourists $M^{t}$, monthly expenditure on cigarette of tourists $m^{l}$, and $M^{l}, N^{t}$ by using the data in V3 system and the formula below: 


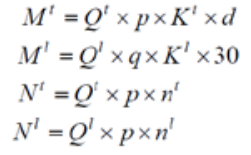

From formula above, we can get the total influence from quantity aspect, the results is shown in Table 1.

Table 1. Total influence from quantity aspect

\begin{tabular}{c|c|c|c|c|c|c|c|c|c}
\hline Year & $\begin{array}{c}\text { Number of } \\
\text { tourist }\end{array}$ & $\begin{array}{c}\text { Monthly } \\
\text { consumption } \\
\text { (carton) }\end{array}$ & $\begin{array}{c}\text { Share of } \\
\text { total(\%) }\end{array}$ & $\begin{array}{c}\text { Monthly } \\
\text { consumption } \\
\text { value } \\
\text { (yuan) }\end{array}$ & $\begin{array}{c}\text { Share of } \\
\text { total(\%) }\end{array}$ & $\begin{array}{c}\text { Actual monthly } \\
\text { consumption(ca } \\
\text { rton) }\end{array}$ & $\begin{array}{c}\text { Share of } \\
\text { total(\%) }\end{array}$ & $\begin{array}{c}\text { Actual monthly } \\
\text { consumption } \\
\text { value(yuan) }\end{array}$ & $\begin{array}{c}\text { Share of } \\
\text { total(\%) }\end{array}$ \\
\hline 2011 & 11245985 & 100817.10 & 9.76 & 2652.77 & 25.79 & 70572 & 6.83 & 1856.90 & 18.05 \\
\hline 2012 & 12590532 & 112870.59 & 10.92 & 2969.93 & 28.87 & 79009 & 7.65 & 2078.95 & 20.21 \\
\hline
\end{tabular}

Cosidering the impact on different category, the results is given in Table 2.

From the questionnaires, the proportion of tourism and local smokers on each cigarette category can be calculated by using the number of sales amount in each category and the number of tourism smokers and local smokers. And then tourism consumption on each category $M_{i}^{t}$ and local consumption on each category $M_{i}^{t}$ can be obtain by multiplying the proportion and consumption amount. So we get:

$$
\begin{aligned}
s_{i}^{t} & =\frac{m_{i}^{t}}{m^{t}} & s_{i}^{l} & =\frac{m_{i}^{l}}{m^{l}} \\
M_{i}^{t} & =M^{t} \times s_{i}^{t} & M_{i}^{l} & =M^{l} \times s_{i}^{l}
\end{aligned}
$$

According to (3) and (4), we can calculate the impact of tourism on consumption structure. As shown in Table 2

Table 2. The impact from structure aspect

\begin{tabular}{c|c|c|c|c}
\hline $\begin{array}{c}\text { Standard of cigarette } \\
\text { category }\end{array}$ & $\begin{array}{c}\text { Self-consumption } \\
\text { amount(carton) }\end{array}$ & $\begin{array}{c}\text { Share of } \\
\text { total(\%) }\end{array}$ & $\begin{array}{c}\text { Self-consumption } \\
\text { expenditure(yuan) }\end{array}$ & $\begin{array}{c}\text { Share of } \\
\text { total(\%) }\end{array}$ \\
\hline $\begin{array}{c}\text { More than 800 } \\
\text { yuan(including) }\end{array}$ & 2360.73 & 77.12 & 236.07 & 114.44 \\
\hline $\begin{array}{c}580 \text { (including)-800 } \\
\text { yuan }\end{array}$ & 10831.59 & 85.16 & 649.90 & 95.90 \\
\hline $\begin{array}{c}\text { 320(including)-580 } \\
\text { yuan }\end{array}$ & 10414.99 & 34.99 & 417.99 & 41.34 \\
\hline $\begin{array}{c}\text { 180(including)-320 } \\
\text { yuan }\end{array}$ & 50269.68 & 45.70 & 1088.44 & 4.31 \\
\hline $\begin{array}{c}115 \text { (including)-180 } \\
\text { yuan }\end{array}$ & 2638.46 & 3.45 & 37.49 & 5.56 \\
\hline 87(including)-115 yuan & 20274.51 & 4.71 & 202.75 & 0 \\
\hline 58(including)-87 yuan & 0 & 0 & 0 & 6.56 \\
\hline 48(including)-58 yuan & 4027.13 & 5.91 & 20.14 & 0 \\
\hline 20(including)-48 yuan & 0 & 0 & 0 & 25.79 \\
\hline Total & 100817.10 & 9.76 & 2652.77 & 40.14 \\
\hline
\end{tabular}

Through the comparison of the tourists and local residents on tobacco consumption.it can be seen that the structure of tourists is superior to local residents with larger proportion of high-end tobacco consumption. Monthly average consumption of tourists has achieved 100817.10 cartons, monthly sales volume reaches to 26.5277 million yuan, revenue from one carton hits 65781.68 yuan' s high which is 1.64 times than mean level of the prefecture. The high proportion of tourists in high-end tobacco consumption reveals that tourists have larger consumption potential, so this market and sales channel for tourist should be given more attention. The appearance of the sum of tourism and local consumption amount sometimes beyond or below the supply amount can be explained by the questionnaire sample may affect the forecasting consumption structure.

The indirect impact refers to the improvement of local consumption structure caused by the promoted per disposable income which is a result of tourism development and expansion. From the data of questionnaires, there is a clear trend that per capital disposable income of tourist regions has a $30.44 \%$ promotion than other regions. It supports the conclusion tourism can significantly improve the living standard in tourism regions. 
By using the same method in Section 3, through the comparison between tobacco consumption structure of tourism and non tourism area. It can be discovered that in the integrated category "more than 115 yuan" , residents in tourist region hold a higher proportion of total sales than residents in non-tourist region. However, in another category "less than 115 yuan", it reveals a thoroughly contrary result.

From Table 3 below, when the revenue improved by 500-1000 yuan, 34.5\% of residents will choose to change brands, and selling price of each packet will averagely increase about 7.59 yuan. When the revenue reaches 1000-1500 yuan, the proportion will achieve at $41.2 \%$, with 11.3 increasing in selling price. When revenue improvement beyond 1500 yuan, these two value will be $47.2 \%$ and 15.74 respectively.

Table 3. The impact of increasing in resident's revnue on tobacco salse.

\begin{tabular}{c|c|c|c|c}
\hline $\begin{array}{c}\text { Monthly } \\
\text { increasing in } \\
\text { revenue }\end{array}$ & Option & $\begin{array}{c}\text { Numb } \\
\text { er of } \\
\text { people }\end{array}$ & $\begin{array}{c}\text { Proportion } \\
(\%)\end{array}$ & $\begin{array}{c}\text { Average } \\
\text { increasing in } \\
\text { selling } \\
\text { price(yuan) }\end{array}$ \\
\hline \multirow{2}{5}{$500-1000$ yuan } & Change & 203 & 34.5 & 7.59 \\
\cline { 2 - 5 } & Not change & 384 & 65.4 & - \\
\hline $1000-1500$ yuan & Change & 242 & 41.2 & 11.31 \\
\cline { 2 - 5 } & Not change & 345 & 58.8 & - \\
\hline More than 1500 & Change & 277 & 47.2 & 15.74 \\
\cline { 2 - 5 } yuan & Not change & 310 & 52.8 & - \\
\hline
\end{tabular}

Furthermore, by using the data above and adopting the following formula:

Monthly increa $\sin g$ amout of sales $=$ Average increa $\sin g$ in selling price

$\times$ Numbers of people change brand $\times$ Average monthly consumption of local residents

It is shown in Table 4 that the increasing of monthly revenue impose great influence on tobacco sales. Larger income improvement always leads to higher growing rate of tobacco consumption.

Table 4. The growth of monthly consumption amout.

\begin{tabular}{c|c|c|c|c|c}
\hline $\begin{array}{c}\text { Monthly } \\
\text { increasing in } \\
\text { revenue }\end{array}$ & $\begin{array}{c}\text { Change } \\
\text { proportion( } \\
\%)\end{array}$ & $\begin{array}{c}\text { Average } \\
\text { increasing in } \\
\text { selling } \\
\text { price(yuan) }\end{array}$ & $\begin{array}{c}\text { Growth of monthly } \\
\text { consumption } \\
\text { amout(yuan) }\end{array}$ & $\begin{array}{c}\text { Average } \\
\text { monthly } \\
\text { consumption } \\
\text { amout(yuan) }\end{array}$ & $\begin{array}{c}\text { Rate of } \\
\text { improvement( } \\
\text { yuan) }\end{array}$ \\
\hline $500-1000$ yuan & 34.5 & 7.59 & 3258.91 & 10287.71 & 31.68 \\
\hline $1500-1500$ yuan & 41.2 & 11.31 & 5799.25 & 10287.71 & 56.37 \\
\hline $1000-1500$ yuan & 47.2 & 15.74 & 9246.10 & 10287.71 & 89.88 \\
\hline
\end{tabular}

\section{Conclusion and Suggestion}

Tourism has driven the improvement of both tobacco sales and structure upgrading in Xishuangbanna prefecture. The main tourist destination is Jinghong city and with a few famous scenic spots in Mengla country. From the data of 2011, Jinghong is the leader of the whole prefecture in single case tobacco composition, per sales, and per consumption amount, which exceed the average level of prefecture by 8.33\%, 8.79\%, 18.15\%. Mengla follows Jinghong with 1.21\%, 4.40\%, 5.69\% exceeding rate respectively. So tourism may have a potential influence on tobacco sales and structure promoting. But how does the influence take effect? The paper divides the impact into two aspects: direct impact and indirect impact.

In analysis of direct impact, we consider both quantity influence and structure influence because it is obviously that the arrivals of tourists will create new demands for local tobacco sales and it is also possible that tourists will have higher taste and tends to purchase high-end brands. This purchasing activity potentially improves the average selling price per packet. In China, cigarette production and sale is tightly controlled by the government. Given a permitted number of production or sales, producing or selling top brand cigarette will increase selling amount and then increase tax income. So consumption structure plays a very important role in tobacco industry. The result has shown that tourists are account for $9.76 \%$ of total consumption in Xishuangbanna, and consumption amount is 
even higher, taking up more than $1 / 4$ of total consumption amount. From the consumption distribution in category, it can be proved that tourists prefer high-end tobacco and expend more in tobacco purchasing than local residents. Tourists consumption is mainly concentrate on the intervals above 320 yuan, while the choice of local residents is generally below 320 yuan. Tourism not only bring quantity grow but also quality purchasing. So it is convinced that along with the increasing of tourist population to Xishuangbanna and the ever-growing requirements for quality tourism products, there must have a potential business opportunity for developing and advertising tourism-related tobacco brands and then making full use of tourist value.

Indirect analysis compares the disposable income of residents in tourist region and non-tourist region. The result shows that per disposable income of local residents in tourist regions is $30.44 \%$ higher than non-tourist regions which can be explained by the leading role of tourism. The comparison of tobacco consumption structure between tourist regions and non-tourist regions reveals the positive relationship between LRDIL and cigarette brand choice. It is discovered that in the integrated category "more than 115 yuan", residents in tourist regions purchase more than non-tourist regions. On the contrary, in the cheaper category "less than 115 yuan”, residents in non-tourist regions are main force of consumption. Residents in tourist region display advantages in tobacco consumption structure. Similar as the analysis above, the structure improvement then lead to the promotion of tobacco sales both in quantity and quality.

Synthesizing the direct and indirect impact analysis, tourism development and expansion surely have a positive influence on tobacco sales. So as to effectively using the promotion effect of tourism, we should strengthen the management of tobacco retailers and carry out training classes for them, building a good purchasing experience for tourists. In order to ensure sufficient supply, more high-end cigarette should be supplied to tourist regions. According to the characteristic of tourists, precision marketing strategy can be taken to improving tourist's motivation of purchasing. Expanding local market especially in tourist region is also a feasible way to increase sales and improve structure based on the research results.

\section{Acknowledgement}

This research was supported by the National Natural Science Foundation of China (Grant 71062006, 71162019, 71362025). Thanks to Xishuangbanna Tobacco Monopoly Bureau, Xishuangbanna Tourist Administration for providing the latest data and giving the opportunity to survey and investigate.

\section{References}

[1] Zhang. F. The impact of tourism on regional economic development: Take Qinhuangdao as an example. China Travel \& Tourism Press, 2003.

[2] Pan. J. M., Z. R. Li. The research on contribution rate of tourism to national economy. China Travel \& Tourism Press, 2004.

[3] Butler. R., C. Clark. Tourism in Rural Areas: Canada and the United Kingdom. Wallingford: CAB International, 1992, 2: pp. 166-168.

[4] Frater. J. M. Farm Tourism in England Planning,Funding,Promotion and some lessons from Europe. Tourism Management, 1983, 9: pp. 167-179.

[5] Oppermann. M. Rural Tourism in Southern Germany. Annals of Tourism Research, 1996, 26(1): pp. 86-102.

[6] Sharpley. R., J. Sharpley. Rural Tourism: an introduction. London: International Thomson Business Press, 1997: 61.

[7] Bai. Y. L., Y. L. Wu, X. S. Cheng. Analyzing tobacco demand in China- current situation and model formation[J]. Acta Tabacaria Sinica, 2007(a, b), 13(3, 4): pp. 154-156; 6-10. 